\title{
O aluno faz-se agente ao se ver como EU, ESCRITOR...
}

\author{
El alumno se hace agente a verse como \\ "YO, ESCRITOR..."
}

\section{The student becomes an agent to be seen as \\ "I, WRITER ..."}

\author{
Mariana de Avellar G. T. Monteiro ${ }^{1}$ \\ Dr $^{\text {a Alessandra Fontes C. da R. K. Pereira }}{ }^{2}$
}

\begin{abstract}
Resumo
O objetivo deste trabalho é relatar a experiência da oficina pedagógica EU, ESCRITOR... A arte de ler, pensar, refletir, saborear, produzir... que foi realizada ao longo do ano de 2016, no município do Rio de Janeiro. A Escola Municipal Finlândia, que recebeu a oficina durante todo o ano, está localizada no bairro do Camorim e atende aos alunos de áreas como as comunidades César Maia, Cidade de Deus e Gardênia Azul. O público da escola é de jovens do $7^{\circ}$ ao $9^{\circ}$ ano do Ensino Fundamental. A oficina EU, ESCRITOR... foi um trabalho desenvolvido visando estimular a capacidade crítica e reflexiva dos alunos a partir de três aspectos fundamentais: o ato de ler, pensar e escrever. Para tanto, foi respeitado o princípio
\end{abstract}

\footnotetext{
${ }^{1}$ Licencianda em Português/Literaturas na UFRJ; Rio de Janeiro, Rio de Janeiro, Brasil; mariana.avellar@hotmail.com

${ }^{2}$ Doutora em Estudos de Literatura; professora de Didática e Prática de Ensino Português - Literaturas; Universidade Federal do Rio de Janeiro; Rio de Janeiro; Rio de Janeiro; Brasil; contato: profa.alessandra.fontes@gmail.com
} 
em que o aluno é agente ativo do seu processo de aprendizagem. Dessa forma, a oficina foi aberta a toda a comunidade escolar e os alunos tinham autonomia para decidir se participariam ou não, além de opinarem sobre o que deveria ser abordado.

Palavras-chave: Oficina; Escola Pública, Autonomia.

\section{Resumen}

El objetivo de este trabajo es relatar la experiencia de la actividad Pedagogica "Yo, escritor... el arte de leer, pensar, reflejar, saborear, producir..." que se realizó a lo largo del año de 2016, en la ciudad de Rio de Janeiro. La escuela municipal Finlândia, que recebió la actividad por todo el año, está ubicada en el barrio de Camorim y atende a los alumnos de la cercania como las comunidades César Maia, Cidade de Deus y Gardênia Azul. El público de la escuela son jóvenes desde el $7^{\circ}$ al $9^{\circ}$ año de la escuela primaria. La actividad "YO, ESCRITOR..." fue un trabajo desarrollado con vistas a estimular la capacidad crítica y reflexiva de los alumnos con tres aspectos fundamentales: el acto de leer, pensar y escribir. A tal fin, se ha respetado el principio en que el alumno és el agente activo de su proceso de aprendizaje. De esa forma, la actividad fue abierta a toda la comunidad escolar y los alumnos tenían autonomía para decidir si participarían o no, además de que opinaban sobre lo que debería de ser trabajado.

Palabras clave: Oficina; Escuela Municipal; Autonomía.

\section{Abstract}

The objective of this work is to relate the experience of the Pedagogic activity "I, WRITER ..." the art of reading, thinking, reflecting, savoring, producing ... that took place throughout the year 2016, in the city Of Rio de Janeiro. The municipal school Finland, which received the activity for the whole year, is located in the neighborhood of Camorim and caters to students in the vicinity such as the communities César Maia, Cidade de Deus and Gardenia Azul. The public of the school is young from the 7th to the 9th grade of elementary school. The activity "I, WRITER ..." was a work developed with a view to stimulating the critical and reflective capacity of students with three fundamental aspects: the act of reading, thinking and writing. To this end, the principle in which the student is the active agent of his learning process has 
been respected. In this way, the activity was open to the whole school community and the students had the autonomy to decide whether or not they would participate, as well as what they thought about what should be worked on.

Keywords: Office; Municipal School; Autonomy.

\title{
1. A importância de ser "Eu, Leitor..." antes de ser "Eu, Escritor..."
}

\author{
"O verbo ler não suporta o imperativo. É uma \\ aversão que compartilha com outros: o verbo \\ amar... o verbo sonhar... É evidente que se pode \\ sempre tentar. Vejamos: "Ama-me!" "Sonha!" \\ "Lê!". "Lê, já te disse, ordeno-te que leias!" \\ - Vai para o teu quarto e lê! \\ Resultado? \\ Nada. \\ Ele adormeceu sobre o livro (...). \\ - Ele acha que as descrições são demasiado longas. \\ Temos de o compreender, estamos no século do \\ audiovisual, evidentemente, os autores do século \\ XIX tinham de descrever tudo... \\ - Mas isso não é razão para o deixarmos saltar \\ metade das páginas!" \\ (Daniel Pennac)
}

Sabemos que, no Brasil, o hábito de ler ainda é algo distante da realidade de grande parte da população. Considerando o número de analfabetos existente em nosso país, é possível imaginarmos o porquê de a leitura ficar em segundo plano. Segundo matéria do Jornal Folha Online ${ }^{3}$ :

No Dia Internacional da Alfabetização (8), o Brasil aparece como o país com o maior número de analfabetos na América Latina, apesar de alguns progressos, segundo dados divulgados pela Organização das Nações Unidas para a Educação, a Ciência e a Cultura (Unesco).

3 Disponível em: http://wwwl.folha.uol.com.br/folha/educacao/ult305u621229.shtml

09/09/2009 - Brasil é o país com maior número absoluto de analfabetos na América Latina. Acessado em $03 / 12 / 2009$ 
No total, 14,1 milhões de brasileiros, o que equivale a 10,5\% da população maior de 15 anos, não sabem ler nem escrever.

A informação destacada acima, apesar de ser datada de 2009, ainda nos serve como resultado para nossas reflexões, pois a mudança não foi tão significativa com o passar do tempo. Atualmente, o Brasil registra queda na taxa do analfabetismo, mas o progresso é lento. Segundo Pesquisa Nacional por Amostra de Domicílios (Pnad), em 2005, 11,1\% das pessoas com mais de 15 anos não sabiam ler e escrever. Dez anos depois, essa proporção caiu para 8\%, de acordo com dados do Instituto Brasileiro de Geografia e Estatística (IBGE).

Dentro de um mundo dirigido pelo pragmatismo, imediatismo e pela eficiência na produção, os textos têm seu espaço reduzido, principalmente os textos literários que se tornam cada vez mais inoperantes no mundo atual. Hoje, não se admite perder tempo, porque "tempo é dinheiro". O ato de ler teve seu espaço reduzido à mera leitura de informação. Por outro lado, a rapidez com que as informações são transmitidas nos permite conhecê-las ao mesmo tempo em que os fatos estão acontecendo, não importa a que distância.

Assim, a leitura por si já se coloca como problema uma vez que ler - e não apenas ler um texto informativo, mas também ler uma obra literária - vem sendo algo cada vez mais visto como "perda de tempo" em face das leituras rápidas da internet e de todos os recursos trazidos pelas inovações tecnológicas.

No contexto escolar, a leitura vem assumindo ares de obrigação e não é raro que os alunos concluam os estudos lendo, porém não compreendendo os textos obrigatórios consequências do imperativo com o qual o verbo ler é utilizado, como indica Daniel Pennac, em nossa epígrafe. Não diferentemente se apresentam as tarefas de escrita na sala de aula, pois a arte de escrever, normalmente, não se desenvolve nas escolas como maneira de abrir caminhos para a imaginação e a reflexão, não sendo entendida como lugar de autoria em que o estudante atua, mas, sim, como reprodução de uma "receita" de escrita, o que exclui qualquer possibilidade de interesse por ela e a prática de uma escrita criativa.

Considerando que o ato de ler é uma atividade complexa, plural e multidirecionada, que segundo Kleiman (1989, p. 13) necessita do engajamento e apoio de muitos fatores memória, atenção, percepção e conhecimentos linguísticos - que precisam ser ativados quando se constrói os sentidos do texto, recusamos a ideia de que a leitura se reduz à simples decodificação de códigos linguísticos e à simples apreensão de informações, pois a tarefa do leitor não é apenas a do reconhecimento de objetos e situações representados no texto, assim como define o próprio Dicionário Aurélio: 
Ler v.t. 1. Percorrer com a vista (o que está escrito), proferindo ou não as palavras, mas conhecendo-as. 2. Ver e estudar (coisa escrita). 3. Decifrar e interpretar o sentido de. 4. Perceber; reconhecer. 5. Adivinhar; predizer. Int. 6.Ver as letras do alfabeto e juntá-las em palavras.

Ainda sobre o ato de ler, segundo Chartier (1999, p. 16), “A leitura não é somente uma operação abstrata de intelecção; ela é engajamento do corpo, inscrição num espaço, relação consigo e com os outros", sendo esse um dos aspectos que procuramos proporcionar aos estudantes da educação básica.

Já em relação à escrita, fundamentamos nossa prática a partir de uma compreensão que vai além da simples função de registro, acreditando ser ela "um instrumento capaz de inventar histórias, expressar emoções ou criar fantasias" (CERRILLO, 2008, p. 183); "geralmente considerado como um processo de construção do pensamento (...) que facilita a expressão do mundo pessoal, das ideias, dos sentimentos [...]" (CABRAL, 2001, p. 9); "ajuda a superar dificuldades expressivas e imaginativas, ao mesmo tempo que desenvolve a fantasia, fomenta as destrezas artísticas, cria o hábito leitor e facilita a comunicação de pensamentos ou de sentimentos, com valor artístico" (Cerrillo, 2008, p. 182); e, não menos importante, “a língua escrita é importante dentro da escola, porque é importante fora dela" (Pereira, 2008, p. 86).

A partir desses pressupostos, percebemos o quanto a formação do leitor e do escritor é importante no período da educação básica, a fim de que a mesma prática continue na futura trajetória acadêmica dos estudantes, sem se tornar um dogma. É nesse sentido que o curso de extensão ${ }^{4} E U$, ESCRITOR... a arte de ler, pensar, refletir, saborear, produzir... ${ }^{5}$ foi criado e se desenvolve, sendo parte da construção material - no campo do ensino da escrita e da formação de

\footnotetext{
${ }^{4}$ Vale ressaltar que a proposta do "Eu, escritor... [...]" começou, no início do ano de 2016, como uma oficina pedagógica e, em meados do ano de 2016, após ser aprovada em todas as instâncias da Universidade Federal do Rio de Janeiro (UFRJ), tornou-se oficialmente curso de extensão da instituição de ensino superior em parceria com escolas públicas do município do Rio de Janeiro. Por isso, em alguns momentos ela poderá ser tratada como oficina e, em outros, como curso.

${ }^{5} \mathrm{O}$ curso de extensão se insere no contexto do Grupo de Ações de Ensino, Extensão e Pesquisa Fórum de Ensino da Escrita - GRAFE, da Faculdade de Educação da Universidade Federal do Rio de Janeiro - UFRJ, do qual uma das autoras deste artigo faz parte. O grupo reúne professores da educação básica e do ensino superior, assim como estudantes de graduação, a fim de propor discussões e pesquisas sobre os saberes teórico-práticos do ensino da escrita na educação básica e na formação de professores na área das licenciaturas de Letras e Pedagogia. Por ser formado por profissionais que atuaram ou ainda atuam na educação básica, mas, ao mesmo tempo, trabalham com a formação de professores para os segmentos fundamental e médio, o GRAFE está concebido como um espaço de ações que privilegia a convergência dos diversos saberes nas duas frentes de atuação.
} 
professores - da indissociabilidade entre ensino, extensão e pesquisa, objetivando estabelecer relação entre três domínios - ler, pensar e escrever - fundamentais para o processo de formação do ser humano enquanto indivíduo crítico, lúcido e reflexivo.

Sendo nós, autoras deste artigo, licencianda do curso de Letras (Português Literaturas) da Universidade Federal do Rio de Janeiro (UFRJ) e a outra, professora atuante na disciplina de Didática Especial de Português - Literaturas e responsável pela Prática de Ensino $^{6}$ de Português e Literaturas, também no curso de Letras da mesma instituição de ensino superior, reconhecemos como parte de nossas responsabilidades - uma enquanto futura professora em formação e a outra enquanto professora de formação de professores - o desafio de se aproximar e de fazer com que os licenciandos vivenciem práticas significativas de leitura e ensino da escrita.

Assim, começou a ser esboçado pelos próprios estudantes do curso de Letras, habilitação Português-Literaturas, ainda em sala de aula, durante as aulas de Didática Especial Português/Literaturas, um projeto pedagógico que priorizasse a leitura e o ensino da escrita, principalmente uma escrita criativa, sendo considerado como especialmente relevante para esses futuros professores de Língua Portuguesa / Literaturas / Produção Textual ${ }^{7}$ incidir a investigação neste âmbito, propondo e analisando situações de aprendizagem com recurso a diversos estímulos (auditivos, visuais e outros), de forma a promover o desenvolvimento dos alunos na chamada escrita criativa, pois "a escrita criativa, mais do que um conjunto de exercícios, funciona como uma possibilidade de aceder a um novo mundo, descoberto para além dos caminhos habitualmente percorridos." (SANTOS, 20087, p. 24).

\section{Como tudo começou: o caso EU, ESCRITOR...}

Como dito anteriormente, a ideia da elaboração de uma oficina pedagógica surgiu durante discussões na turma de Didática Especial de Português - Literaturas. A proposta feita pela professora Alessandra Fontes foi a de que cada licenciando elaborasse um projeto pedagógico que priorizasse e incentivasse a leitura e a escrita. A finalidade prática dos projetos produzidos era a de que eles saíssem do papel para a sala de aula, na tentativa de

\footnotetext{
${ }^{6}$ Momento no qual os licenciando devem cumprir o estágio obrigatório e não remunerado nas escolas conveniadas à Universidade Federal do Rio de Janeiro (UFRJ), totalizando a carga horária de 400 horas.

${ }^{7}$ Disciplina denominada em algumas escolas como Redação.
} 
chegarem ao espaço escolar (campo de estágio). Especificamente no caso da proposta $E U$, ESCRITOR... A arte de ler, pensar, refletir, saborear, produzir..., após receber o trabalho de três licenciandas que atuavam como estagiárias na mesma escola, a professora, responsável pela disciplina e pela supervisão e orientação do estágio, verificou vários pontos de contato entre eles, principalmente, nas sugestões de um trabalho de produção de escrita criativa. Além das semelhanças entre os projetos pedagógicos, a escola, campo de estágio das três licenciandas, apresentava interesse em receber propostas de atividades que deveriam ocorrer após as aulas regulares. Assim, os três projetos elaborados individualmente passaram a ser um projeto único, produzido a oito mãos ${ }^{8}$.

Não foi necessário muito tempo para que a proposta deixasse de ocupar o campo das especulações e ideias para se tornar uma realidade a ser alcançada. Desta maneira, a oficina pedagógica EU, ESCRITOR... foi idealizada e conduzida pela professora Alessandra Fontes (UFRJ), pelo professor Washington Kuklinski ${ }^{9}$ (SME-RJ) e as licenciandas do curso de Letras da UFRJ: Fabieli Colombo, Mariana Monteiro e Thamires da Matta.

O objetivo central que norteou toda a elaboração da oficina foi o de formar indivíduos críticos e reflexivos a partir dos atos de ler, pensar e escrever. Para tanto, é reconhecida a importância de uma postura ativa do aluno no seu processo de ensino-aprendizagem, em que se faz necessária a conquista da posição de agente.

Para atingir seu objetivo, o enfoque da EU, ESCRITOR... é trabalhar os diversos modos de articular a língua em contextos variados ao se propor a explorar a comunicação a partir de diferentes tipologias e gêneros textuais. A partir de então, a oficina assume um compromisso político de, nas possibilidades do texto literário, explorar também o cânone com esses estudantes que, por muitas vezes, têm o acesso a bens culturais negligenciado, assim como aborda Antonio Candido em seu texto $O$ direito à literatura:

A organização da sociedade pode restringir ou ampliar a fruição deste bem humanizador [literatura]. O que há de grave numa sociedade como a brasileira e que ela mantém com a maior dureza a estratificação das possibilidades, tratando como se fossem compreensíveis muitos bens materiais e espirituais que são incompreensíveis. Em nossa sociedade há fruição segundo as classes na medida em que um homem do povo está praticamente privado da possibilidade de conhecer e aproveitar a literatura de Machado de

\footnotetext{
${ }^{8}$ Responsáveis pela elaboração do projeto: Alessandra Fontes, Fabieli Colombo, Mariana Monteiro e Thamires da Matta.

${ }^{9}$ Professor da Secretaria Municipal de Educação do Rio de Janeiro; responsável por ministrar aulas da disciplina de História; em 2016, atuava na Escola Municipal Finlândia; propulsor e coordenador pelo funcionamento do curso na escola.
} 
Assis ou Mário de Andrade. Para ele, ficam a literatura de massa, o folclore, a sabedoria espontânea, a canção popular, o provérbio. Estas modalidades são importantes e nobres, mas é grave considerá-las como suficientes para a grande maioria que, devido à pobreza e à ignorância, é impedida de chegar às obras eruditas. (2011, p.188)

Dessa maneira, a oficina tem o compromisso de apresentar, reconhecer e explorar o cânone com o estudante, sem que essa atitude desmereça ou desvalorize as manifestações literárias que fazem parte do repertório cultural dos estudantes. Essa postura está diretamente relacionada à prática pedagógica que valoriza o conhecimento prévio dos discentes e de seus gostos do lado externo da escola como uma possibilidade renovadora que pode trazer à tona o escritor e o leitor crítico, a partir do que lhe dá prazer. Afinal, a imposição de textos que, supostamente, deveriam ser supervalorizados em detrimento de outros, não seria coerente com uma prática pedagógica que visa o aluno como agente de seu processo de ensinoaprendizagem.

Após os objetivos da EU, ESCRITOR... terem sido traçados e o seu plano pedagógico formulado, apresentado e aprovado pela $7^{\mathrm{a}} \mathrm{CRE}$ (Coordenadoria Regional de Educação), no dia seis de maio de 2016, a oficina deixou de ser um projeto e foi recebida pela Escola Municipal Finlândia. A instituição, localizada no bairro do Camorim, no Rio de Janeiro, atende os alunos das comunidades César Maia, Asa Branca, Preguiça, Cidade de Deus e Gardênia, sendo todas afastadas e de difícil acesso aos polos culturais da cidade, o que, entre outros fatores, é um grande obstáculo para que os estudantes dessa região tenham contato com atividades culturais, como teatro, exposições e museus, por exemplo.

A oficina foi aberta a toda a comunidade escolar, sem nenhum tipo de obrigatoriedade ou vínculo com notas. Os encontros ocorriam nas tardes de sexta-feira, de 14:30 às 16:30. É importante destacar, também, que a Escola Municipal Finlândia atende estudantes do $7^{\circ}$ ao $9^{\circ}$ do Ensino Fundamental e todos foram convidados a participar igualmente da oficina, sem agrupamento a partir do ano escolar. Assim, como a EU, ESCRITOR... não possui nenhum tipo de vínculo obrigatório e/ou público alvo específico, o interesse e a motivação dos estudantes inscritos no curso foi a metodologia utilizada para chamar novos discentes para conhecer e participar dos encontros.

Para o início da atuação fez-se necessária a elaboração de um projeto pedagógico que contemplasse o planejamento de todas as oficinas que seriam realizadas ao longo do ano de 2016. Nesse cronograma, no geral, os encontros eram norteados a partir de textos de autores como Clarice Lispector, Machado de Assis, Carlos Drummond de Andrade e Manuel 
Bandeira. No entanto, desde o princípio, foi assumido o compromisso de não adotar nenhuma estrutura rígida o suficiente para limitar a atuação ativa dos estudantes. Essa postura foi fundamental para o desencadear das oficinas.

Ao decorrer dos encontros, um fenômeno foi observado: quando os estudantes gostavam muito da oficina, a reação espontânea deles era, ao final, sair cantando os seus raps preferidos em voz alta. Esse contentamento e prazer dos estudantes despertava a curiosidade de todos que tinham contato com eles, a fim de saber o que tinha acontecido para deixá-los tão entusiasmados, já no fim de uma semana cansativa. Esse fato não poderia ser ignorado. Logo, o planejamento da EU, ESCRITOR... foi flexibilizado para poder contemplar, também, leituras rimadas trazidas não só pelos elaboradores das oficinas, bem como, pelos discentes. Essa mudança do cronograma, além de ter se mostrado necessária, foi muito boa tanto para os alunos, que se sentiram verdadeiramente contemplados pela oficina, quanto para os elaboradores, em especial, para as licenciandas que conseguiram vivenciar uma prática pedagógica horizontal que, de fato, está disposta a escutar o estudante e a tratá-lo como indivíduo e não somente como membro de uma massa homogeneizada.

A EU, ESCRITOR... acarretou consequências para todos os envolvidos. No mês de novembro, os estudantes participantes da oficina promoveram o Sarau das Artes para toda a comunidade escolar, no qual eles foram responsáveis pelos mínimos detalhes, desde a organização - escolha da data, público convidado e composição do convite - até a elaboração do cronograma e composição do material a ser apresentado.

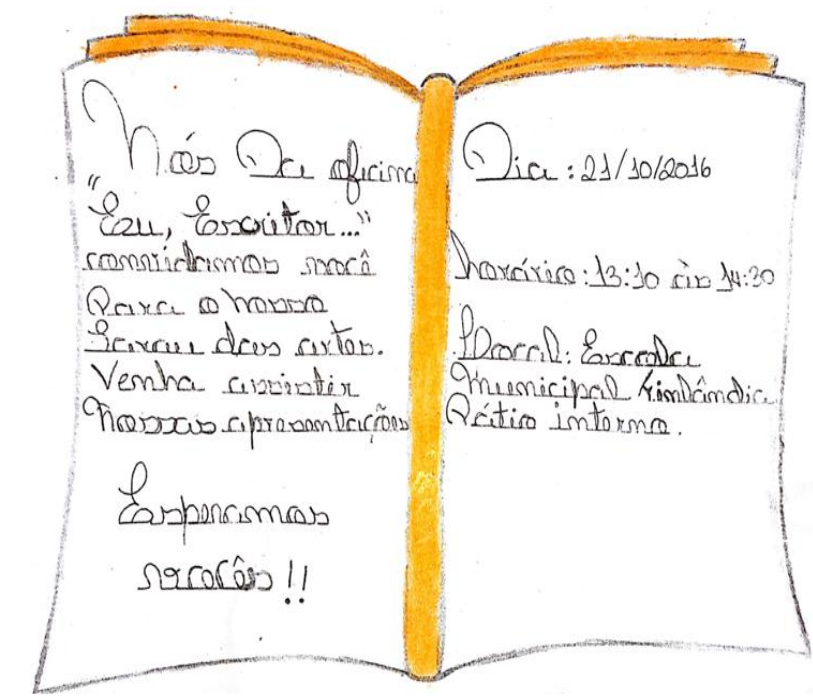

Convite para o Sarau das Artes elaborado pelos estudantes 


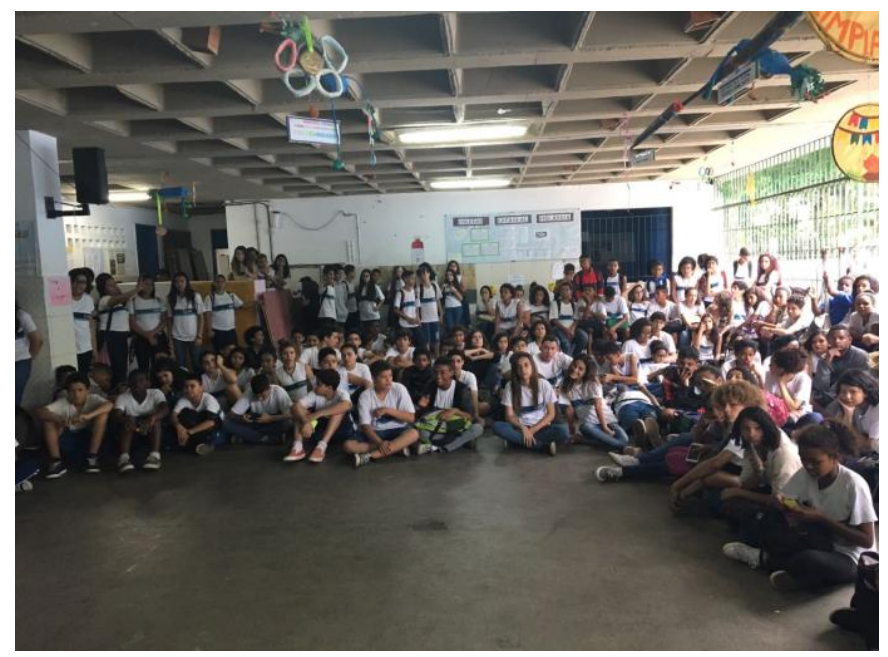

Membros da EU, ESCRITOR...

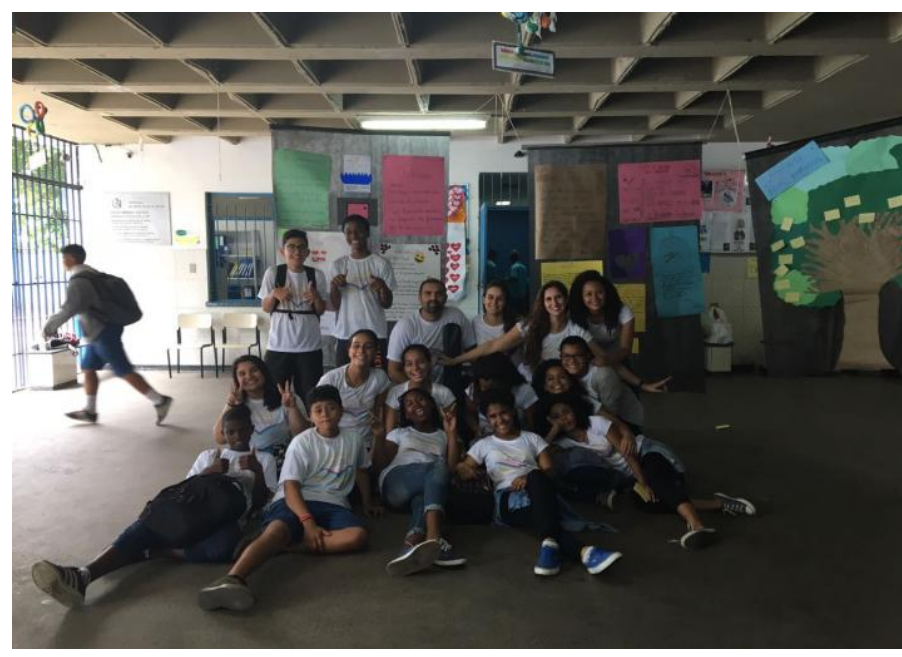

Plateia do Sarau das Artes

A contaminação dos princípios da $E U$, ESCRITOR... aconteceu não só nos estudantes da Escola Municipal Finlândia, bem como no corpo docente que se sentiu motivado a promover, também, atividades extracurriculares e fazer uso, nas aulas regulares, de textos de alguns autores lidos nas oficinas. Além disso, a oficina passou a ser um curso de extensão da Universidade Federal do Rio de Janeiro e, em 2017, ganhou um novo espaço: a Escola Municipal Frei Gaspar.

\section{Considerações finais}

O curso de extensão EU, ESCRITOR... evidenciou a necessidade de uma relação íntima entre teoria e prática, na formação docente e na docência. Afinal, durante as oficinas, nós, licenciandas, pudemos, de fato, experimentar essa possível relação a partir da teoria estudada ao longo das aulas de Didática Especial de Português - Literaturas e da prática efetivada na Escola Municipal Finlândia. Ao findar do percurso que traçamos em 2016, a impressão que ficou é a de que Paulo Freire, em seu Pedagogia da Autonomia, já havia descrito o que vivemos na $E U$, ESCRITOR...:

"Se, na verdade, o sonho que nos anima é democrático e solidário, não é falando aos outros, de cima para baixo, sobretudo, como se fôssemos os portadores da verdade a ser transmitida aos demais, que 
aprendemos a escutar, mas é escutando que aprendemos a falar com eles." (2016, p. 110)

Dessa maneira, uma prática de ensino vertical e inflexível mostrou-se inviável não só nos textos teóricos estudados durante a formação do docente, como também foi atestada na vivência durante o curso de extensão. Além disso, ressaltamos que para conseguir atingir o objetivo de praticar a escrita criativa com os estudantes da escola a relação horizontal e a atitude de ouvi-los foram fundamentais.

\section{Referências}

BARROS, Manoel de. Exercícios de ser criança. Rio de Janeiro: Salamandra, 1999.

CABRAL, M. A. Ideias para escrever. Rio de Janeiro: Edições Contraponto, 2001.

CANDIDO, Antonio. O direito à Literatura. In: Vários escritos. São Paulo: Duas Cidades, 2011.

CERRILlO, P. A escrita criativa dos alunos. Revista do Programa de PósGraduação em Letras da Universidade de Passo Fundo, 177-179, 2008.

DIAS, M. Como abordar... a escrita expressiva e lúdica: técnicas e propostas didáticas. Porto: Areal Editores, 2006.

FREIRE, Paulo. Pedagogia da autonomia. Rio de Janeiro: Paz e Terra, 2016.

GRIBEL, Christiane. Minhas férias, pula uma linha, parágrafo. Ilustrações de Orlando. São Paulo: Richmond Educação; 2009.

MANCELOS, J. Introdução à Escrita Criativa. Lisboa: Edições Colibri, 2011.

MARTINS, V. M. T. A qualidade da criatividade como mais valia para a educação. Revista Millenium, 29, 295-312, 2004.

NORTON, C. Os mecanismos da escrita criativa. Lisboa: Temas e Debates - Actividades editoriais, 2001.

PENNAC, Daniel. Como um romance. Rio de Janeiro: Rocco, 1993.

SANTOS, M. F. \& Serra, E. (2011 - $4^{\text {a }}$ edição). Quero ser Escritor: Manual de escrita criativa para todas as idades. Mirandela: Oficina do Livro.

SANTOS, M. F. (2008). Escrita Criativa: uma janela aberta para um novo mundo. Noesis, 72, 34-37. 
SARTORI, V. \& FIALHO, F. A. P. Desenvolvimento da criatividade no ensino básico: o papel do professor como facilitador do processo criativo. Programa de Pós-Graduação em Engenharia e Gestão do Conhecimento, 1-19, 2009. 